\title{
AUTORIA, COMUNIDADE E A NOÇÃO DE PERTENCIMENTO: PRÁTICAS DE ESCRITA LITERÁRIA E SUAS INSTÂNCIAS DE LEGITIMAÇÃO SOCIAL
}

\author{
Luis Fernando Prado Telles ${ }^{1}$
}

RESUMO: O presente artigo pretende refletir sobre o caráter relativo do processo de legitimação social promovido pelas práticas de escrita literária. Para tanto, mobiliza os conceitos de autoria e de comunidade, cuja relaçáo parece se resolver em uma noçáo fluida de pertencimento. Com esse objetivo, convoca o conceito de discurso constituinte para pensar o estatuto do discurso literário, propondo, ao final, uma reflexão acerca do processo de legitimação social da literatura nas comunidades virtuais do mundo digital.

Palavras-chave: Legitimação social. Autoria. Comunidade. Pertencimento.

\section{Authorship, community, and the belonging notion: practices of literary writing and its instances of social legitimation}

ABSTRACT: The present article intends to reflect on the relative character of the social legitimation process promoted by the literary writing practices. Thus, it mobilizes the concepts of authorship and community, whose relationship seems to be solved in a fluid notion of belonging. Therefore, it summons the constituent discourse concept to consider the status of

\footnotetext{
${ }^{1}$ Universidade Federal de São Paulo - Guarulhos (SP), Brasil. E-mail: If.telles@hotmail.com
} DOI: 10.1590/CC0101-32622018183548 
literary discourse. At the end, a reflection on the process of social legitimation of literature in virtual communities of the digital world is proposed.

Keywords: Social legitimation. Authorship. Community. Belonging.

\section{A LITERATURA E O CONCEITO DE LEGITIMAÇÃO}

A proposição do tema acerca da relação entre as práticas de escrita literária e suas formas de legitimação social conduz-me a bilidades: uma delas pressupóe considerar as práticas de escrita literária no âmbito de uma esfera que precisa de certas instâncias autenticadoras, digamos assim, para ganhar certa legitimação social, ou seja, tornar-se aceita, ou legal, num sentido lato; e a outra pressupóe a esfera da prática de escrita literária como uma instância propositora de legitimação social, pois seria um lugar especial ocupado pelo discurso, altamente valorizado pela tradição, como lembra Eagleton (1994).

No primeiro caso, o valor das práticas de escrita literária, ou da literatura de um modo geral, não estaria necessariamente na própria literatura, mas fora dela, ou seja, aquilo que a faria ou não valorizada ou legitimada socialmente estaria em outras esferas, aquém ou além de seus domínios. Considerada desse modo, a forma de enxergar a literatura não diferiria muito do modo como a linguística avalia as diferenças linguísticas ou variaçóes, a partir da premissa básica de que uma variedade linguística não possui um valor em si, mas que as variantes valem o que valem os seus falantes ou o que estes representam. No caso em discussão, o postulado pode aqui ser transposto ao estudo do fenômeno literário, no sentido de que as escritas literárias valeriam o que valem os seus autores ou o que representam na sociedade em que se inserem.

No segundo caso, a literatura seria entendida como um espaço discursivo de prestígio, capaz de garantir legitimidade social a quem a pratica e a quem a consome, seja em termos individuais ou coletivos. Sob esse prisma, a literatura seria um lugar especial de promoção de certo 
grau de reconhecimento e prestígio social, o que poderia ser traduzido pela ideia genérica de legitimação.

Contudo, essas duas formas de considerar o processo de legitimação da literatura, apesar de distintas, podem ser entendidas como estando imbricadas, uma vez que, se desconsiderarmos que a literatura não possui um valor em essência, entáo o que a constituiria como um lugar de prestígio seria o processo anterior de legitimação efetivado por aquelas outras instâncias. Nesse caso, mesmo entendendo a literatura como um espaço especial de legitimação social, o que lhe garantiria esse status não estaria necessariamente nela. Só seria assim no caso de as práticas de escrita literária (a literatura de modo geral) serem consideradas como portadoras de um valor em si. Nesse caso, o que está em discussão aqui, me parece, é uma questáo de fundo já bem antiga, que diz respeito ao problema geral da autonomia da arte.

\section{A AUTONOMIA DA ARTE E AS INSTÂNCIAS DE LEGITIMAÇÃO}

A questão da autonomia da arte pode ser resumida pela oposição entre duas proposiçóes: a que encara a arte, e no caso a literatura, a partir dos critérios ditados por ela mesma e, portanto, julga-a como portadora de um valor intrínseco, forte, capaz de se impor e de promover a legitimação social de quem a produz e de quem pode dela usufruir; e a de que a arte/literatura tem o seu valor determinado sempre contingencialmente e, portanto, avalizado pelas instâncias de legitimaçáo que lhe são externas. Esse é o debate que conduz, por exemplo, à discussão acerca do problema do cânone em literatura ${ }^{1}$. Esse tema está atrelado, de modo simplificado, a uma relação binária entre aquilo que é central, principal (eleito como importante e relevante), e aquilo que é marginal, porque assim o seria a partir da perspectiva do próprio centro. No caso da esfera literária, o cânone literário serviria, em grande medida, para a manutenção de uma tradição que pode estar vinculada à afirmação de uma série de outros valores, tais como os que se pautam no reforço de certa concepçáo de unidade linguística ou nacional. Sob esse prisma, a justificativa para conceber um cânone, em geral, se dá por meio da ideia de manutenção de certo patrimônio cultural. O problema, portanto, de vincular a valorização do canônico à esfera da representação cultural é 
que a própria ideia de cultura é passível de ser contestada ou relativizada. A crítica ao cânone, portanto, é inevitavelmente conduzida a uma crítica da própria ideia de cultura. É sob esse viés que se dá o movimento teórico de relativização ou de ataque ao cânone. Culler (1999) demonstra que a relativização do cânone literário advém do surgimento da perspectiva dos estudos culturais, os quais proporiam, nesse sentido, a mobilização de forças com o objetivo de opor a cultura popular a duas frentes hegemônicas: de um lado, a cultura de massa e, de outro, a cultura de elite, que, apesar de não servir à cultura de massa, ainda assim serviria à classe dominante, porque estaria imbuída dos valores tradicionais responsáveis pela manutenção do status quo social, político e econômico.

Em geral, o debate indicado por Culler (1999) gira em torno de uma tensão polarizada entre a literatura eleita e a literatura excluída. Em relação a essa dupla em tensão, haveria um terceiro elemento, um polo de força bastante relevante, mas que rivalizaria com ambas as forças da polaridade indicada, e que se constituiria na literatura dita de massa. A literatura canônica se constituiria, portanto, negativamente a partir da oposição dupla a esses dois polos: o dos excluídos e injustamente desvalorizados e o dos incluídos por força da lógica do mercado e, assim, muitas vezes indevidamente valorizados. Para ter sua existência garantida, a literatura canônica dependeria, segundo a perspectiva de alguns teóricos, daquilo que designam como instâncias de legitimação, as quais seriam de várias ordens, como "a universidade, os suplementos culturais dos grandes jornais, as revistas especializadas, os livros didáticos, as histórias literárias etc." (ABREU, 2006, p. 49).

\section{A RELATIVIZAÇÃO DO LITERÁRIO PELAS VÁRIAS INSTÂNCIAS DE LEGITIMAÇÃO}

Contudo, se tomarmos aqui o sentido das práticas de escrita literária de um modo mais abrangente, suas instâncias de legitimação social devem ir além daquelas determinadas e válidas para definir o que seria considerado como canônico. Em outro sentido, o que se deve levar em consideração é o caráter relativo e dinâmico do que seria o social, ou seja, legitimar algo como sendo grande literatura não significa, consequentemente, garantia de legitimação social em todos os casos. Seria, antes, a 
legitimação de um estrato ou de uma parcela do social. É preciso levar em conta, pois, a complexidade do que se deve entender por legitimação social da literatura, visto que esta há de ser considerada também em suas múltiplas possibilidades. Nesse sentido, uma literatura considerada de estrato popular, não canônica, pode ter garantida a sua legitimação social, bem como a literatura dita de mercado ou de massa. $\mathrm{O}$ fato é que as legitimaçóes e suas instâncias não são únicas, mas várias, e relativas entre si. É importante, portanto, pensarmos para além das instâncias de legitimação do canônico, visto que estas, atualmente, já não funcionam de modo hegemônico (se é que funcionaram em algum momento).

\section{A LEGITIMAÇÃO SOCIAL DA LITERATURA A PARTIR DA RELAÇÃO ENTRE AS NOÇÕES DE COMUNIDADE, AUTORIA E PERTENCIMENTO}

Em se considerando, mesmo que estrategicamente, a triangulação proposta por Culler (1999), entre as esferas da literatura dita erudita, a popular e a de mercado, cada uma delas encontraria sua legitimação por meio de diferentes instâncias, mas também é possível haver fenômenos literários que sejam legitimados socialmente pelas três instâncias ao mesmo tempo.

Diante desse quadro, arriscaria uma hipótese acerca de dois aspectos que se fazem fundamentais no processo de legitimação social nas diferentes esferas indicadas.

O primeiro diz respeito ao fato de que o processo de legitimação social náo pode ser pensado de maneira uniforme, abrangente e totalizante; antes, deve ser pensado localmente, comunitariamente. Por exemplo, as tradicionais instâncias legitimadoras da literatura, as "Academias de Letras", de um modo geral, sejam aquelas entendidas como agremiaçóes de notáveis canônicos, como a Academia Brasileira de Letras, sejam as universitárias, deixaram há muito de ter monopólio e papel totalizante no que toca à legitimação social das práticas literárias e da promoção de autores. Podem fazer algum sentido quando se pensa num determinado nicho da prática literária, o considerado erudito, ou o da educação formal. Contudo, quando se pensa do ponto de vista da inserção social, as práticas literárias devem ser tomadas a partir de sua circunscrição ao nível mais micro. É nesse sentido que a legitimação ocorre comunitaria- 
mente, seja para considerarmos o que está sendo produzido na esfera cult das cenas das grandes metrópoles, do mundo das livrarias e dos prêmios literários, seja para pensarmos o que está sendo produzido no âmbito da cultura de periferia ou mesmo da chamada cultura popular ou regional, como é o caso emblemático da literatura de cordel. Cada uma dessas esferas obedece a uma dinâmica de um sistema de valores próprio, com acordos e contingências muito particulares, mas que podem eventualmente se cruzar. Do mesmo modo que um autor dito erudito pode ser popularizado e ganhar valorização social por isso, um autor representativo de determinado nicho social também pode ser alçado ao nível de literatura com "L" maiúsculo. Ambas as esferas, por seu turno, podem ser conduzidas a outra provação, a do mercado. Quando legitimadas nesse âmbito, passam a se constituir também como literatura de massa.

O segundo aspecto que se faz fundamental no processo de legitimação social das práticas literárias em todas as diferentes esferas diz respeito ao fato de que tal processo, mesmo que circunscrito a termos comunitários, ou locais, passa pelo fenômeno de sedimentação de um "nome de autor"2.

Em seu famoso ensaio de 1969, O que é um autor?, Foucault (2006) procura descrever a relação do texto com o autor partindo do questionamento de como um texto aponta para seu autor, produzindo o efeito de que este seria uma entidade anterior e exterior ao próprio texto. Assim, examina o funcionamento do nome próprio como "nome de autor", explorando os efeitos que ele produz quando é atribuído a um texto ou conjunto de textos. Para Foucault (2006), o "nome de autor" afeta a prática do discurso e serve como princípio de classificação e agrupamento. Uma dispersão de textos, quando referida a um mesmo "nome de autor", passa a funcionar como unidade, obra. Como consequência, o fato de atribuir um "nome de autor" a um texto afeta sua forma de circulação (sua validade, sua legitimidade, seu valor relativo). Para Foucault (2006), o "nome de autor" permite individualizar uma prática discursiva e afeta seu modo de circulação na sociedade; de acordo com este teórico, somente algumas práticas discursivas, consideradas como obras, podem ser atribuídas a um "nome de autor". Gêneros cotidianos não apontariam, segundo Foucault (2006), um autor na sua origem e, portanto, não seriam referidos a um "nome de autor". Para esses casos, Foucault reserva o conceito de "função-autor". A “função-autor" não garante, pois, a constituição de um "nome de autor"; este, por seu turno, só se configura a partir de um siste- 
ma literário em funcionamento organizado a partir da relação autor, obra e público leitor, e isto se dá atualmente, como vimos, num nível micro e de modo mais segmentado e setorizado, porque circunscrito a comunidades leitoras, muitas vezes não comunicantes. É por isso que os "nomes de autores" fazem ou deixam de fazer sentido a depender do contexto em que se encontram. É desse modo que ocorre a legitimação social dos produtores de certas práticas de escrita literária quando são alçados à condição de "nomes de autores"; por outro lado, uma determinada produção literária, ou prática de escrita literária, poderá promover a legitimação social de certo grupo na medida em que representar os seus valores e princípios. A noção fundamental, aqui, é a de pertencimento. Determinada prática literária ou determinado "nome de autor" serão legitimados a depender do grau de pertencimento a certos valores comunitários.

\section{A LITERATURA COMO DISCURSO CONSTITUINTE}

Apesar de o próprio conceito do que seja o literário poder ser relativizado, bem como as instâncias de legitimaçáo serem igualmente relativas e variadas, num sentido mais abrangente, ainda assim é possível pensar o literário como um tipo de discurso específico que guarda uma natureza comum, independentemente do modo como se dá na prática, a partir de diferentes comunidades, formas de pertencimento e modos de constituição de "nomes de autores". Nas várias esferas mencionadas, a literatura pode ser entendida como um tipo de discurso que Maingueneau (2000) considera como discurso constituinte. Para pensar o conceito de discurso constituinte, Maingueneau parte do chamado primado do interdiscurso na análise do discurso, ou seja, o de que "a identidade de um discurso se constitui e se alimenta através de outros discursos" (MAINGUENEAU, 2000, p. 5). Nesse sentido, o literário, entendido como um discurso, se consolida não isolada ou essencialmente, mas a partir da relação com outros discursos. Essa relação está circunscrita a uma comunidade, ao mesmo tempo em que tem o poder de circunscrever uma noção de comunidade. Maingueneau (2000) entende o literário como um tipo especial de discurso que, ao lado de outros, como o filosófico e o religioso, partilha certo número de propriedades comuns, mas tais discursos "possuem, com efeito, um estatuto singular: zonas de fala 
em meio a outras e falas que pretendem preponderar sobre todas as outras" (MAINGUENEAU, 2000, p. 6). Sob essa perspectiva, o discurso constituinte seria aquele que tem a pretensão de fundar e não de ser fundado. Ele é ao mesmo tempo auto e heteroconstituinte: na medida em que se impóe como preponderante em relação aos outros discursos, também os convoca para referendar essa preponderância, constituindo-os como discursos secundários. Segundo Maingueneau (2000), o discurso constituinte determinaria e seria determinado por aquilo que ele entende como archéion da produção verbal de uma sociedade:

$\mathrm{O}$ archéion associa assim intimamente o trabalho de fundação no e pelo discurso, a determinaçáo de um lugar associado a um corpo de enunciadores consagrados, e à elaboração de uma memória. [...] Um dos pontos mais notáveis é que os discursos constituintes são múltiplos, em concorrência, embora cada um deles possa ter, em um momento ou em outro, a pretensáo de ser o único detentor do archéion (MAINGUENEAU, 2000, p. 7).

Segundo essa argumentação, equaciona-se a situação de o discurso literário poder ser vário em suas manifestaçóes e relativo a depender da comunidade de que se origina e que ajuda a fundar, pois uma das características do discurso constituinte, no caso o literário, seria a de guardar em sua essência a pretensão de "ser o único detentor do archéion”, apesar de, na prática, manifestar-se plural e até em concorrência. É nesse sentido que o literário, enquanto discurso constituinte, deve ser visto a partir de uma pluralidade, apesar de se pretender totalizante em sua fundação. Assim, a comunidade a que pertence determinado discurso literário é ao mesmo tempo fundante e fundada por ele. A noção de pertencimento, pois, deve ser entendida sob o prisma de uma "comunidade discursiva”, já "que a comunidade é cimentada por discursos que são, no entanto, o produto desta própria comunidade discursiva” (MAINGUENEAU, 2000, p. 8). O discurso constituinte encerra em si o que essa noção relativizada de legitimação social do literário pretende demonstrar, ou seja, o caráter ambíguo do discurso literário de ser condicionado localmente, comunitariamente, mas conter em si uma pretensão universal, totalizante, pois, conforme indica Maingueneau (2000, p. 8), 
os discursos constituintes têm um alcance global, eles pretendem o conjunto da sociedade, mas eles são elaborados localmente, em lugares institucionais restritos que imprimem sua marca sobre sua produção, que a moldam através de uma maneira de viver.

Os discursos constituintes, nesse sentido, inscrevem-se na sociedade, na medida em que a ajudam a fundar-se; em certo aspecto, portanto, as noçóes de comunidade e de pertencimento não são atributos do discurso literário, mas, antes, completam sua fundação graças ao discurso literário, no caso, visto como discurso constituinte. Segundo Maingueneau (2000, p. 10),

o discurso constituinte não é um simples vetor de ideias, ele articula, através do dispositivo enunciativo, textualidade e espaço institucional. Ele investe na instituição que o torna possível legitimando (ou deslegitimando) o universo social onde ele se inscreve. Há constituição precisamente na medida em que o dispositivo enunciativo funda, de maneira, por assim dizer, performativa, sua própria possibilidade, fazendo o possível para parecer que ele extrai essa legitimidade de uma Fonte da qual ele seria a encarnaçáo (o Verbo revelado, a Natureza, a Razão, a Lei...).

Esse processo de fundação performativa da possibilidade do discurso constituinte se desenrolaria, segundo Maingueneau (2000), em três registros: por meio de sua cenografia, que seria a representação que o discurso constrói de sua própria situação de enunciação; da mobilização de seu código de linguagem, que lhe permite validar sua autoridade; e de sua voz, que fixa um ethos associado a sua cenografia e a seu código de linguagem.

Vista, assim, como um discurso constituinte, a literatura, entendida em suas variaçóes de acordo com as comunidades discursivas a que pertence, molda a própria noção de autoria a partir dessa noção mais abrangente de ethos. Ser autor, portanto, nesse âmbito das comunidades discursivas, significa estar embebido de autoridade ou, dito de outro modo, ser o portador da autoridade fundada discursivamente por uma coletividade. Segundo Maingueneau (2000, p. 11), 
a propriedade essencial dos discursos constituintes é seu estatuto no interior do interdiscurso: uma vez que os discursos "ordinários" neles se apoiam, eles devem se apoiar diretamente em princípios transcendentes, no que chamei aqui de "archéion". Tais discursos participam de campos discursivos em constante conflito; eles são profundamente hierarquizados, conforme o grau de proximidade com sua Fonte; são produzidos por pequenas comunidades, embora tratem de problemas básicos da sociedade em geral; são definidos por um modo específico de circulação no interdiscurso (arquivamento, comentário, citação, etc.); o que eles dizem (“ideias", "doutrinas") não pode ser separado da cena discursiva através da qual eles foram produzidos e que thes conferiu autoridade.

Pensar a literatura como um discurso constituinte ajuda a resolver aquelas questóes colocadas inicialmente. Sobre a questáo da legitimação social, foi apresentado o questionamento se a literatura seria ela própria uma instância de legitimação social ou legitimada socialmente por outras instâncias. Segundo o raciocínio desenvolvido por Maingueneau (2000), a literatura, vista como discurso constituinte, teria por natureza promover a legitimaçáo, pois se colocaria como um discurso fundante, preponderante, ou, como caracteriza esse autor, um discurso primeiro. Para Maingueneau (2000), portanto, a inscrição discursiva que ajuda a fundar uma comunidade ou uma sociedade, num sentido mais lato, depende de uma hierarquia de gêneros discursivos/textuais que operam a dinâmica do discurso constituinte: há os discursos primeiros (discursos fonte) ou originais, em que se inserem os literários, e os discursos segundos (que comentam, retomam, explicam, divulgam os primeiros). Nesse sentido, seria da natureza do discurso que se pretende literário funcionar como discurso primeiro; no mesmo sentido, sua existência depende dessa dinâmica operada com os discursos segundos. No caso, seriam os discursos segundos que comporiam as instâncias de legitimação social do literário. Portanto, faz parte da natureza do discurso constituinte, segundo essa dinâmica, legitimar (por ser fundador, primeiro) e ser legitimado (por ser objeto dos discursos segundos). O discurso literário, entendido como discurso constituinte, evoca, portanto, uma autonomia ao mesmo tempo em que convoca outros discursos a se constituírem como secundários, legitimadores de sua centralidade. 
Assim, independentemente da comunidade de circulação do discurso literário, seja na esfera popular, cult, erudita ou de massa, para pensarmos em termos esquemáticos, como vimos anteriormente a partir de Culler (1999), o discurso literário, como discurso constituinte, sempre se arvorará de uma essencialidade de discurso primeiro, por um lado, e terá, por outro, sua dinâmica confirmada pelos discursos segundos, que comporiam as instâncias de legitimação, as quais variam de acordo com as comunidades discursivas.

Pensar o processo de legitimação social da literatura em termos comunitários requer que ampliemos também a própria noção de comunidade em nossa contemporaneidade digital. Cabe a nós entender o que permanece e o que de novo se impóe nessa dinâmica.

\section{DA COMUNIDADE ÀS TEIAS DAS REDES SOCIAIS: O EXCLUSIVO E O TOTALIZANTE}

Mesmo aquilo que poderíamos pensar como sendo característico de nosso mundo contemporâneo, como a profusão de comunidades ligadas em formato de teia — as famosas "redes sociais" —, tem em sua origem a noção de agrupamento comunitário, o qual, por seu turno, não tem nada de original ou contemporâneo. $\mathrm{Na}$ base da ideia de comunidade fechada está o princípio de que aqueles que a ela pertencem são "diferenciados", "escolhidos", "especiais" em relação aos que dela não fazem parte. As "redes sociais" seguem o princípio da união pela exclusão: a comunidade une aqueles que possuem algo em comum e, logo, exclui os demais. O próprio Facebook foi criado a partir dessa lógica. Contudo, nesse caso específico, o seu sucesso depende de uma lógica irônica e paradoxal que dá a todos a exclusividade do direito de a ele pertencer. É assim que se vai, portanto, da ideia de comunidade para a de "rede social". No entanto, há também "redes sociais" redirecionadas à ideia originária de comunidade, na medida em que passam a aglutinar pessoas que possuem o mesmo interesse e partilham valores comuns. É o caso, por exemplo, das plataformas virtuais de publicação que também funcionam como "redes sociais". Há dezenas delas, mas cito como exemplo apenas duas, a título de ilustração. A Widbook é uma rede social na qual o usuário consegue publicar seu livro e ver comentários e avaliaçóes 
a respeito dele. Curiosamente, esta é uma empresa de três jovens da cidade de Campinas (SP) que possui sede em São Francisco, Califórnia, Estados Unidos, no famoso Vale do Silício. Esta plataforma, contudo, nasceu inspirada em outra, a Wattpad, considerada a maior comunidade de leitores e escritores do mundo. Além de possibilitar que o usuário publique seu livro, interaja com leitores e conheça outras obras, a plataforma já revelou vários novos autores para o mercado editorial, entre os quais se destaca a americana Anna Todd, cujo primeiro livro, After, teve mais de um bilhão de acessos e seis milhóes de comentários.

Tais comunidades acabam por reproduzir virtualmente o que encontramos postulado na teoria pelo conceito de sistema literário, composto por autor, obra e público leitor, com a diferença de que nesses ambientes virtuais tais componentes são mais fluidos e obedecem a outra dinâmica, uma vez que os atores não são fixos e podem passar de um papel a outro simultaneamente. Nesse sentido, por conta da dinâmica de tais comunidades, a fronteira entre discursos fechados e discursos abertos de que fala Maingueneau (2000) parece diminuída. Segundo o teórico francês, os primeiros seriam os "discursos dos quais os leitores são escritores potenciais ou efetivos de enunciados do mesmo gênero" (MAINGUENEAU, 2000, p. 9), enquanto os segundos seriam os "discursos onde os leitores, em número muito mais restrito que os escritores, não estão em posição de escrever enunciados do mesmo gênero" (MAINGUENEAU, 2000, p. 9). Em certo sentido, portanto, o discurso literário parece tornar-se menos "fechado", se assim é possível considerarmos, por conta dessa nova dinâmica imposta pelas comunidades virtuais.

Em tais comunidades, o sucesso de uma narrativa pode ser medido quase que instantaneamente, à medida que as leituras vão se realizando. Os leitores, por seu turno, podem fazer críticas antes mesmo de a narrativa ter sido completada, e os autores podem transformar suas histórias e modificar sua técnica conforme os feedbacks dos leitores, recebidos quase em tempo real. $\mathrm{O}$ processo de legitimação social da prática literária nesses espaços é totalmente sui generis e obedece a uma dinâmica particular, em que a produçáo literária, a leitura e a sua crítica se fazem quase que concomitantemente. Contudo, a lógica que parece guiar essa dinâmica não aparenta ser nada nova, estando ainda atrelada ao paradigma do sucesso em larga escala e, portanto, em sua origem, condicionando certa prática literária à conformação de gêneros e de estilos já sedimenta- 
dos, que atendam também a um público com um gosto pré-formatado. Nesse sentido, essas plataformas que apresentam maneiras totalmente novas de prática de escrita literária revelam-se como expressóes das lógicas mais retrógradas de legitimação social do literário, aquelas guiadas pela fácil aceitação e pela capacidade de gerar renda em larga escala, o que acaba por se traduzir em uma palavra perigosa: sucesso.

\section{A SAÍDA PARADOXAL DO DISCURSO LITERÁRIO}

A busca da literatura pelo sucesso de público e de mercado, contudo, não é uma marca exclusiva da nossa contemporaneidade e, especificamente, dessas plataformas de publicação convertidas em redes sociais. Isso parece ser atestado pela própria história do gênero romanesco, em outros tempos. Vejamos o que diz Walter Siti (2009), em seu curioso texto "O romance sob acusação":

O romance do século XVIII inglês seria impensável sem a busca do sucesso de público: o próprio Fielding, que é o mais culto e que tenciona reagir ao descrédito do romance, admoesta que "um autor deveria considerar-se náo como um senhor que dá um banquete particular ou beneficente, mas como quem dirige um restaurante". Certamente, não faltam defensores do romance (e romancistas) que tentaram reabilitá-lo aproximando-o da epopeia e da tragédia, ou que afirmam, como Pierre-Daniel Huet em 1670, que um romance "não é julgado pelo número, mas pela competência de quantos o estimam”. É necessário, porém, chegar a Rousseau para que se ouça qualquer um dizer que "um romance deve ser vaiado, odiado, feito em pedaços pelas pessoas elegantes". Nos séculos XIX e XX, um setor do romance se torna um gênero de elite, mas um outro setor muito amplo continua a ser um gênero de massa: as acusaçóes que se faziam ao romance são as mesmas que ora se fazem à ficção televisiva (SITI, 2009, p. 171).

Uma visada diacrônica sobre a literatura, como a que nos oferece o trecho citado, permite vislumbrar o caráter relativo e mutável do prestí- 
gio social de determinados gêneros literários, como é o caso do romance. Segundo o que dispóe a citação, o gênero romanesco seria não apenas um tipo de literatura feita para as massas, mas, inclusive, um gênero literário que serviria ao sentido contrário da libertação intelectual do homem rumo a sua autonomia. Seria, pois, um caminho de alienação e condução das massas, uma literatura desprestigiada socialmente e, portanto, pouco legítima.

Em contrapartida, na contemporaneidade, vemos muitas vezes o mesmo gênero romanesco ser evocado como caminho de salvação frente à automatização das massas. De gênero desprestigiado, o romance passa a ser visto como um caminho de libertação e emancipação do homem. Isso é o que nos aconselha Tzvetan Todorov (2012), em seu recente $A$ literatura em perigo:

Desde a época do Iluminismo, pensamos que a vocação do ser humano exige que ele aprenda a pensar por si mesmo, em lugar de se contentar com as visóes do mundo previamente prontas, encontradas ao seu redor. Mas como chegar lá? No Emílio, Rosseau usa a expressão "educação negativa" para designar esse processo de aprendizagem, sugerindo que se mantenha o adolescente longe de livros, a fim de afastá-lo de toda a tentação de imitar a opiniáo de outrem. Pode-se, entretanto, raciocinar de maneira distinta, já que os preconceitos, sobretudo os atuais, não precisam de livros para se instalarem de forma permanente no espírito dos jovens: a televisão já passou por lá! Os livros dos quais ele se apropria poderiam ajudá-lo a deixar as falsas evidências e libertar seu espírito. [...] A leitura de romances tem menos a ver com a leitura de obras científicas, filosóficas ou políticas do que com outro tipo bem distinto de experiência: a do encontro com outros indivíduos. [...] O que o romance nos dá não é um novo saber, mas uma nova capacidade de comunicação com seres diferentes de nós; nesse sentido, eles participam mais da moral do que da ciência. Sendo o objeto da literatura a própria condição humana, aquele que a lê e a compreende se tornará não um especialista em análise literária, mas um conhecedor do ser humano (TODOROV, 2012, p. 79-93).

Pelo até aqui exposto, talvez seja válido considerarmos que a literatura, em si, tem valor e legitimidade social não necessariamente pelo 
seu caráter afirmativo e peremptório, mas, ao contrário, por se negar a enquadrar-se nas amarras de um único paradigma de legitimação e, inclusive, por colocar em questão os próprios princípios que muitas vezes a legitimam social e culturalmente.

Diante disso, e para encerrar, o mais coerente talvez seja assumir a incoerência do caráter ambíguo e paradoxal do que quer que seja a literatura. Para tanto, peço novamente emprestadas as palavras de Culler (1999, p. 47):

A literatura é o ruído da cultura, assim como sua informação. É uma força entrópica assim como um capital cultural. [...] A literatura é uma instituiçáo paradoxal porque criar literatura é escrever de acordo com fórmulas existentes - produzir algo que parece um soneto ou que segue as convençóes do romance - mas é também zombar dessas convençôes, ir além delas. A literatura é uma instituiçáo que vive de expor e criticar seus próprios limites, de testar o que acontecerá se escrevermos de modo diferente.

Entendida como discurso constituinte, a literatura se impóe como um discurso-limite. Como diz Maingueneau (2000, p. 6), os discursos-limite estão "situados sobre um limite e lidando com o limite, eles devem gerar textualmente os paradoxos que implicam seu estatuto". Considerada desse modo, como o lugar do convencional e também do demolidor, a literatura expóe "os paradoxos que implicam seu estatuto" e, assim, pode se apresentar como uma saída para a libertação das amarras das inúmeras teias e redes em que frequentemente nos vemos enredados atualmente.

\section{REFERÊNCIAS}

ABREU, M. Cultura letrada: literatura e leitura. São Paulo: Editora da Unesp, 2006.

COMPAGNON, A. O demônio da teoria: literatura e senso comum. Belo Horizonte: Editora da UFMG, 2010.

CULLER, J. Teoria literária: uma introdução. Tradução de Sandra Vasconcelos. São Paulo: Beca, 1999. p. 47. 
EAGLETON, T. Introdução: o que é literatura? In: Teoria da literatura: uma introdução. São Paulo: Martins Fontes, 1994. p. 1-18.

FOUCAULT, M. O que é um autor? In: . Ditos e escritos - estética: literatura e pintura; música e cinema. Rio de Janeiro: Forense Universitária, 2006. MAINGUENEAU, D. Analisando discursos constituintes. Revista do GELNE, v. 2, n. 2, p. 1-12, 2000.

SITI, W. O romance sob acusação. In: MORETTI, Franco (Org.). A cultura do romance. Traduçáo de Denise Bottman. São Paulo: Cosac Naify, 2009. p. 171.

TELLES, L.F.P. A literatura como objeto de conhecimento: notas sobre o cânone e a pesquisa acadêmica. Fronteiraz, São Paulo, n. 14, p. 30-50, 2015.

TODOROV, T. A literatura em perigo. Tradução de Caio Meira. Rio de Janeiro: Difel, 2012.

\section{NOTAS}

1. Retomo, nesta parte 2, de modo resumido, considerações acerca do conceito de cânone em literatura já desenvolvidas em artigo de minha autoria: TELLES, 2015.

2. No âmbito da teoria literária, a discussão sobre a autoria e o conceito de autor é bastante polêmica, tanto que o próprio teórico francês Antoine Compagnon (2010) dedica a este tema o mais longo capítulo de seu livro $O$ demônio da teoria: literatura e senso comum. Compagnon (2010) considera o lugar do autor o ponto mais controvertido nos estudos literários. A questão é antiga, lembra ele, e remonta à passagem da Idade Média ao período renascentista, mas o ponto fulcral da discussão se desenvolve na modernidade, a partir da relativizaçáo das noçôes de intencionalidade e de sinceridade românticas, que conferiram ao conceito de autor a aura de gênio, sujeito agraciado pelo dom da criação original. A discussão é longa e a lista de teóricos que já se debruçaram sobre ela não é pequena, mas, em termos bem sintéticos, é possível pautar o debate a partir da dicotomia entre as teorias que propuseram a desconstruçáo do conceito de autor e aquelas que, diante de tal desconstruçâo, apresentaram sua reformulaçáo em outros termos. Michel Foucault é um dos autores que propóem essa reformulação a partir dos conceitos "nome de autor" e "função-autor", inserindo na discussão os condicionantes sociais e históricos.

Recebido em 02 de agosto de 2017.

Aceito em 23 de março de 2018.

(C) 2018 Centro de Estudos Educação e Sociedade - CEDES Este é um artigo de acesso aberto distribuído nos termos de licença Creative Commons. 